\title{
SISTEMA E MEIOS DE TRANSPORTE EM SÃO PAUlO A PARTIR DA OBRA DE SÉRGIO BUARQUE DE HOLANDA
}

System and means of transport in São Paulo based on Sérgio Buarque de Holanda's work

\section{Guilherme}

\section{GRANDI}

(D) ggrandi@usp.br

Universidade

de São Paulo

São Paulo, SP, Brasil

\section{RESUMO}

O presente artigo trata dos caminhos por terra e dos cursos fluviais que se entrecruzavam e se complementavam por toda a área da "Paulistânia", formando um complexo sistema de vias de transporte, tema exaustivamente abordado por Sérgio Buarque de Holanda em três dos seus trabalhos como historiador: Monções, Caminhos e fronteiras e Capítulos de expansão paulista. O objetivo do artigo é demonstrar a essencialidade da obra de Buarque de Holanda para a pesquisa historiográfica sobre a introdução e o desenvolvimento dos meios de transporte, primeiro, na capitania e, em seguida, na província de São Paulo. Conclui-se, por meio do exame de tais trabalhos, que houve na Região Centro-Sul do país, entre os séculos XVI e XIX, uma evolução gradativa das modalidades de transporte que vai do apresamento e dos descimentos de indígenas até o advento das ferrovias, passando pelas monções de povoado e pelas tropas de muares.

Palavras-chave: Meios de transporte, Sérgio Buarque de Holanda, São Paulo.

\begin{abstract}
This paper covers the paths on land and rivers that crisscrossed and joined throughout the area of "Paulistânia", forming a complex system of transportation routes. The theme was exhaustively addressed by the Brazilian author Sérgio Buarque de Holanda in three of his works as a historian: Monções, Caminhos e fronteiras and Capítulos de expansão paulista. The aim of the article is to demonstrate the essentiality of Holanda's works for the historiographical research on the introduction and development of transports first in the Captaincy and then in the Province of São Paulo. By the analysis of such works, we conclude that, between the sixteenth and nineteenth centuries, there was a gradual evolution of the transport modalities in the South-Central Region of the country that went from the entrapment and descents of indigenous until the advent of railroads, passing by the "monções" of settlement and troops of mules.
\end{abstract}

Keywords: Means of transport, Sérgio Buarque de Holanda, São Paulo. 
evolução das vias e dos meios de transporte é um dos episódios mais marcantes da expansão paulista e, portanto, representativo da colonização lusitana no Brasil ao longo da extensa zona entre o planalto de Piratininga, o litoral e o interior do país. O início do povoamento e do estabelecimento dos primeiros caminhos percorridos a pé pelos portugueses de São Paulo, foram narrados por viajantes, cronistas e historiadores de diversas épocas e estão registrados em vasta documentação primária, como cartas forais, petições de sesmarias, diários de viagens, entre outros documentos quinhentistas, seiscentistas e setecentistas.

As diversas narrativas se referem, invariavelmente, aos fenômenos das bandeiras (ou entradas) e monções. Bandeirantes e monçoeiros são, ao lado de índios e mamelucos, os agentes históricos por excelência desse movimento de desbravamento, ocupação, povoamento e fundação de arraiais, vilas e cidades. ${ }^{1}$ Uma vez estabelecidos, os povoados formados às margens dos caminhos terrestres e das rotas fluviais serviam de base de abastecimento e de ponto de pouso, chegada, ou de partida de aventureiros e exploradores que buscavam metais, gentio para prear e gêneros da terra com algum valor comercial apreciável e que, portanto, pudessem ser inserido no circuito mercantil colonial.

É possível dizer, mesmo mediante aproximação grosseira, que a empresa bandeirante que operou em meio à imensa faixa de terra entre as vertentes das serras da Mantiqueira e de Paranapiacaba foi motivada pela busca por metais preciosos. Suas reservas, contudo, foram descobertas ao custo da expulsão e subjugação dos "tupis inimigos, índios de guerra, mas também índios de lavoura, cobiçados, por isto, dos sitiantes e traficantes de peças", como nos informa Sérgio Buarque de Holanda (2014b, p. 229). A propósito, parte apreciável da obra do historiador é referência fundamental para a compreensão acerca da origem do sistema e meios de transporte utilizados pelos paulistas, pois consiste, ainda hoje, em material de consulta imprescindível aos interessados pelo estudo do movimento expansivo dos colonizadores, uma vez fundada a vila de São Vicente em 1532.

Tempos depois, em 1709, criou-se a capitania de São Paulo e Minas de Ouro e, no ano seguinte, houve a nomeação pela Coroa portuguesa do primeiro capitão-geral, Antônio de Albuquerque Coelho de Carvalho, responsável por governar uma área vastíssima resultante das bandeiras e correspondente ao que hoje se conhece pelos estados de São Paulo, Minas Gerais, Goiás, Tocantins, Mato Grosso, Mato Grosso do Sul, Paraná, Santa Catarina e até a região missioneira do Rio Grande do Sul, constituída pelos jesuítas por meio de sua obra de evangelização de indígenas. Essa imensa região do Centro-sul do país, da qual só escapavam uma parte da capitania de São Pedro, o Rio de Janeiro e o Espírito Santo, Ellis Junior (1951) a denominou "Paulistânia".

A porção territorial das minas de ouro adquire sua autonomia administrativa em $1720 \mathrm{com}$ a criação da capitania das Minas Gerais. Sua divisa com a capitania de São Paulo se dava pelos cursos dos rios Sapucaí e Grande e pela serra da Canastra até o rio Paranaíba, ao Sul e Sudeste do atual território do estado de Minas Gerais. Outras alterações administrativas vão ser levadas a cabo com o passar do tempo: o desmembramento de Santa Catarina ocorrerá em 1738; as capitanias de Goiás e 
Mato Grosso datam de 1748; entre esta data e 1765, a capitania de São Paulo ficou subordinada à do Rio de Janeiro, quando daí por diante voltaria a ter sua autonomia administrativa. Em 1822 as capitanias passam ao status de províncias e, em 1853, surge a província do Paraná como desmembramento da província de São Paulo. Em suma, a Paulistânia era um imenso território resultante da faina bandeirante que ampliava, em termos consideráveis, as áreas de ocupação da América portuguesa e que se pautava fundamentalmente por uma economia de subsistência voltada ao mercado interno.

O tema do presente artigo são os caminhos por terra e os cursos fluviais que se entrecruzavam e se complementavam por toda a área da Paulistânia num complexo sistema de vias de transporte. Tema exaustivamente abordado por Buarque de Holanda em três dos seus trabalhos que se encontram reunidos em obra recente organizada por Laura de Mello e Souza e André Sekkel Cerqueira, intitulada Capítulos de expansão paulista, principal material de referência deste artigo. Nela é possível captar a consistência analítica e a beleza estilística dos textos do historiador, que se debruçou por pelo menos três décadas em um projeto de pesquisa sobre a sina semovente dos paulistas. Nesse volume, encontram-se dois capítulos do livro inacabado do autor, O Extremo Oeste, e outros três capítulos reescritos do livro Monções, publicado em 1945. A esses dois trabalhos, soma-se Caminhos e fronteiras, de 1957, livro que sintetiza essa agenda de pesquisa de Sérgio Buarque e que, sem sombra de dúvidas, está entre as principais contribuições do autor à historiografia brasileira, ao lado, é claro, do aclamado Raízes do Brasil, de 1936.

Para os propósitos deste artigo, trabalhos de outros estudiosos, especialmente de historiadores, também são levados em conta com o objetivo de se estabelecer uma interlocução acerca da temática que nos anima: o estabelecimento dos meios e sistema de transporte em São Paulo. Ressalva-se, no entanto, que a referência bibliográfica principal a qual nos valemos corresponde ao conjunto formado pelos três trabalhos de Sérgio Buarque supramencionados (Monções, Caminhos e fronteiras e Capítulos de expansão paulista). Busca-se, portanto, demonstrar a essencialidade de tais estudos para a pesquisa historiográfica sobre os primórdios dos meios de comunicação e transporte, primeiro na capitania e, em seguida, na província de São Paulo.

Para tanto, estruturou-se o presente artigo em três partes, além desta introdução e das considerações finais. Na primeira parte, destacamos como Buarque de Holanda aborda o avanço dos sertanistas sobre o vale do rio Paraíba, mais precisamente sobre a região do médio Paraíba, e do consequente estabelecimento das primeiras formas de transporte ligando os povoados que ali se formaram no século XVII com o litoral paulista e o Rio de Janeiro. Quais eram e como se deu a implantação dessas formas de locomoção? Com qual finalidade eram utilizados tais meios, o que transportavam, e a quem serviam? Qual legado deixaram no espaço e na relação fixada entre seus promotores e usuários? Afinal, qual era o objetivo desses primeiros povoadores, desses sertanistas, em ocupar essa que é uma das primeiras regiões da capitania a ser efetivamente colonizada? Na segunda parte, examinamos o tratamento dado por Buarque de Holanda às monções, ou seja, às navegações fluviais destinadas ao comércio entre São Paulo e Mato Grosso após a descoberta das jazidas de ouro 
em Senhor Bom Jesus do Cuiabá. Um questionamento que se impõe é: haveria uma relação direta entre as entradas paulistas e as monções de povoado no que tange ao estabelecimento de um sistema viário comum e compartilhado? E, na terceira e última parte, relacionamos as contribuições do historiador paulista a respeito das tropeadas, isto é, o transporte feito por lombo de animais organizados em tropas, com a atividade açucareira que se estabeleceu a partir do chamado "quadrilátero do açúcar", área compreendida entre os municípios paulistas de Jundiaí, Sorocaba, Piracicaba e Mogi-Guaçu, na qual se destacam Campinas e Itu. Neste caso, importa aprofundarmos o exame sobre o papel de alguns grandes comerciantes e fazendeiros que se nobilitaram pelos serviços prestados à administração real portuguesa com o abastecimento de muares, dentre outros bens, a cobrança de impostos e a prestação de serviços como o de melhoramento dos caminhos e estradas que, sem dúvida alguma, consistiu em elemento dinamizador importante ao impulsionar à produção açucareira em São Paulo voltada para a exportação, já que o açúcar foi o primeiro gênero de vulto produzido pelos paulistas em sua inserção no comércio atlântico.

\section{Na lapa do mundo}

É absolutamente plausível pensar que os luso-brasílicos, especialmente os paulistas, "cairo na lapa do mundo"2, isto é, a eles coube sair pelos sertões em busca de novas terras que pudessem ter alguma utilidade econômica, alguma forma de exploração comercial, o que vai ao encontro do que parte da historiografia tem afiançado a respeito do bandeirantismo. Fenômeno arquetípico da expansão colonizadora na América, expedições de desbravamento, empresa de prear indígenas e prospectar riquezas minerais, enfim, elemento central do movimento de colonização portuguesa do Novo Mundo levado a cabo por capitães de guerra e fiéis vassalos reinóis (TAUNAY, 1961).

A pesquisa histórica sobre o movimento das bandeiras confirma qual era o principal fator que animava desbravadores e aventureiros a participarem das expedições sertanistas: a busca pelo eldorado, ou seja, a descoberta de ouro e outros metais preciosos na zona delimitada pelo Tratado de Tordesilhas (1494). Embora a fundação da capitania de São Vicente, por Martim Afonso de Souza, tenha ocorrido mediante carta régia de 20 de novembro de 1530, foi somente depois, em 1549, com o estabelecimento do governo-geral da Bahia, sob o comando do governador Tomé de Souza, que as expedições bandeirantes foram alavancadas com o objetivo declarado de descobrir ouro no interior do continente.

Ao passar em revista a produção historiográfica mais tradicional sobre o bandeirantismo, Monteiro (1994, p. 76-78) observa, no entanto, que muitas expedições foram inicialmente decepcionantes do ponto de vista minerador. O surto bandeirante ocorrido entre 1628 e 1641 esteve, segundo o autor, muito mais relacionado ao desenvolvimento da economia do planalto do que à demanda por escravos no litoral açucareiro. Ou seja, parece pouco plausível pensar que a transferência de cativos do sertão, ou das reduções jesuíticas, para os engenhos de açúcar teria ocorrido de maneira sistemática, de modo que o eventual comércio dessa mão de obra capturada pelos paulistas representava, provavelmente, o excedente da economia do planalto. 
A partir da região vicentina, no litoral paulista, as entradas iam sendo organizadas em número crescente a ponto de, passado a fase das expedições malogradas, se definir uma complexa e engenhosa rede de caminhos tanto terrestre quanto fluvial, resultado de mais de três séculos de prospecção, exploração e povoamento, a começar pelo século XVII que, segundo Taunay (1961, p. 14), marca o período áureo das entradas no Brasil. Em contrapartida, para Buarque de Holanda (2014b, p. 34-35), a principal vocação dos paulistas estava muito mais associada à locomoção e, portanto, ao ato de abrir e constituir vias de comunicação, uma vez que a mobilidade se colocava como uma das poucas alternativas à constante escassez de "recursos disponíveis para a sustentação do ideal comum de estabilidade", leia-se para o estabelecimento de alguma cultura agrícola significativa. Segundo o próprio autor:

Aquela sociedade meio aluvial constituída no planalto vicentino irá manter-se ainda por dois séculos ou mais em situação instável e imatura, que deixa espaço ao maior intercurso com a gente nativa. Sua vocação está no caminho, que convida ao movimento, não na grande lavoura, que cria indivíduos sedentários (HOLANDA, 2014b, p. 34).

Moniz Bandeira (2012) observa que os primeiros bandeirantes do planalto de Piratininga objetivavam chegar ao Alto Peru, principalmente após a descoberta de prata nas minas de Potosí, por muito tempo o alvo privilegiado das incursões pelo sertão. Facilitadas a princípio pela anexação do Reino de Portugal ao da Espanha (1580-1640), as entradas pelo interior do continente definiram rotas e desenvolveram materiais de transporte, aperfeiçoando-os com o passar do tempo, até a descoberta das minas de ouro nas regiões de Minas Gerais, Mato Grosso e Goiás, entre o decorrer do século XVII e o início do XVIII. Para o autor, tais expedições consistiam fundamentalmente em empreendimentos econômicos, nos quais se investiam volumosos cabedais.

Já para Vilardaga (2019, p. 686-687), a tarefa de compreender aquilo que marcou em essência o movimento das bandeiras não é algo simples, haja vista que tais expedições armadas buscavam atender a demandas variadas. Organizadas de diversas formas, as bandeiras cumpriam múltiplas funções ao percorrerem caminhos previamente trilhados pelos indígenas, em geral carregadas de mercadorias para autoabastecimento e para a realização de trocas. O reino português as incentivava com vistas também a atingir seus objetivos geopolíticos e fronteiriços, embora não se tivesse muito controle sobre a execução da empreitada em si, o que impunha dificuldades em se formar a tropa (ou a frota de embarcações no caso do transporte fluvial) e no provimento das diversas ocupações funcionais para sua desejada realização. Nenhum progresso significativo foi experimentado, no entanto, antes do emprego generalizado de cavalares para os trajetos mais extensos (HOLANDA, 2014b, p. 40). ${ }^{3}$

Evidências coligidas por Buarque de Holanda mostram, todavia, que a anseio em buscar metais preciosos teve influência moderada sobre o ânimo inicial dos colonizadores paulistas. Suas palavras são inequívocas nesse sentido: 
A cobiça do ouro representou, em realidade, fator tão pouco decisivo da penetração quanto o desejo atribuído por alguns autores aos sertanistas de São Paulo de ampliar deliberadamente a área da colonização lusitana. [...]

A demora com que, no planalto de Piratininga, se tinham introduzido costumes, tradições ou técnicas provenientes da metrópole não deixaria de ter ali fundas consequências. Desenvolvendo-se a atividade colonizadora com muito mais soltura do que nas outras capitanias, tendia a processar-se através de uma incessante acomodação a condições locais (HOLANDA, 2014b, p. 37-39).

Na realidade, nem sempre a expectativa dos capitães das bandeiras, bem como dos responsáveis pelas frotas das monções, era atingida e, muitas vezes, as baixas humanas e as perdas materiais se faziam consideráveis. A busca por ouro foi o fator propulsor do povoamento da região do vale do Paraíba e, ao mesmo tempo, forneceu o estímulo que faltava aos paulistas para se definir os melhores cursos d'água, os trechos mais facilmente navegáveis, bem como os trajetos mais curtos e menos acidentados por terra entre serras e frondosas florestas de mata atlântica.

De São Paulo à região do médio Paraíba para se chegar ao Rio de Janeiro ou à área mineradora, expedicionários costumavam embarcar em canoas à altura do sítio denominado Aldeia da Escada até pouco abaixo de Guaiapacaré (freguesia de Nossa Senhora da Piedade de Guaipacaré, atual município de Lorena), e, na vila da Conceição da Paraíba (hoje Jacareî) fundada em 1653, iniciava-se o percurso a pé ou a cavalo (HOLANDA, 2014b, p. 236). A despeito da sua importância como ponto de referência para o serviço de condução das tropas, logo para a definição do percurso mais recomendável às expedições pelo médio Paraíba, Jacareí consistiu em uma derivação do movimento de fixação de outros dois povoados, mais antigos, que se formaram durante a primeira metade do século XVII: as vilas de Santana das Cruzes de Moji-Mirim (atual Mogi das Cruzes) e de São Francisco das Chagas de Taubaté (conhecida hoje apenas por Taubaté). Sobre esses importantes núcleos populacionais, cujas origens resultaram das expedições bandeirantes, Buarque de Holanda (2014b, p. 233) menciona que:

\begin{abstract}
A atribuição de autonomia municipal aos povoados que ali se criam, a Taubaté em 1643, a Guaratinguetá em 1651, a Jacareí em 1653, parece denunciar não só a viva sedução exercida em dado momento por toda a área, já livre, desde há muito, da barreira indígena, como ainda a preocupação dos governos em fazer ocupá-la efetivamente, nela instalando, tal como se fizera em Moji das Cruzes, órgãos locais de poder.
\end{abstract}

Moji, portanto, parece ser o povoado mais antigo dessa região por onde passou as expedições de André de Leão em 1601 e de Nicolau Barreto no ano seguinte. Resultante do estabelecimento de moradores que ali se fixaram por ordem do governador d. Francisco de Souza, ao final do século do descobrimento, o povoado 
de Moji formou-se por "parcialidades tupiniquins desgarrados de Piratininga" e, muito provavelmente, por remanescentes dos tamoios que sobreviveram ao massacre do seu povo. Buarque de Holanda nos informa que a essa época tribos nativas desbarataram os homens das bandeiras de Antônio de Macedo e Domingos Luís Grou, o que nos faz compreender pelo menos uma parte das motivações que levaram a Câmara da vila de São Paulo a solicitar ao capitão Jorge Correia que guerreasse com o gentio dessa região, contrariando os valores disseminados pelos jesuítas da Companhia de Jesus (HOLANDA, 2014b, p. 228).

Pouco antes da fundação da vila de Moji, no tempo da sesmaria pioneira conferida a Gaspar Vaz em 1608, já se cogitava a existência de uma passagem dali para o mar "como uma das razões para levantar-se pelourinho". Alcançado o objetivo de descobrir as minas de ouro, seria possível embarcar os reais quintos à povoação de Moji, que "mandou fazer da Angra dos Reis" d. Francisco de Souza em 1611 (HOLANDA, 2014b, p. 238).

Moji se notabilizou pela presença de bom roçado. De acordo com documentos seiscentistas, produzia-se na vila víveres que eram estratégicos para o abastecimento das tropas expedicionárias, como milho, feijão-branco, algodão, cana, mandioca, banana, inhame e até trigo, este último em quantidade reduzida. Desde a fundação da vila, em 1611, a preocupação de povoar e ocupar todo o caminho que levava às jazidas preciosas está presente no ânimo dos governos. Um dos principais moradores da vila, Francisco Vaz Coelho, foi um dos contemplados na Matrícula da Gente Carijó ao receber peças forras num total de nove unidades, as quais lhe são dadas com a obrigação de as empregar no benefício das minas. Já em 1617, Gonçalo Correia de Sá, atendendo à provisão de Salvador de Sá, governador das capitanias de baixo, ordenou que fosse aberto um caminho ligando o porto de São Sebastião, no litoral norte paulista, às margens do rio Paraíba, saindo de Moji. A motivação dessa diligência era a necessidade de encurtar o trajeto em direção ao sertão (HOLANDA, 2014b, p. 244).

De acordo com fontes manuscritas da Coleção José Bonifácio, do Instituto Histórico e Geográfico Brasileiro, haviam duas picadas na mata entre Moji e a marinha de Santos, nas quais uma delas, a de Bertioga, era há tempos utilizada pelo gentio da terra, ou seja, bem antes de se conhecer o caminho da Piaçaguera velha, utilizado por Martim Afonso de Souza em sua subida de São Vicente ao campo de Piratininga em 1532 (HOLANDA, 2014b, p. 238-239).

Outra senda que dava acesso à costa marítima era a de São Sebastião, vila fundada em 1636. O responsável pela abertura desse trecho foi Gonçalves Correia, que recebeu provisão para tal feito do seu pai, Salvador de Sá, a 7 de janeiro de 1617 , que lhe ordenou, entre outras coisas, "que abrisse o caminho da marinha para o rio Paraíba e fizesse explorar umas terras do sertão em que se dizia haver prata e ouro." (HOLANDA, 2014b, p. 239). Tal via também tinha como ponto de partida a vila de Moji das Cruzes e, após a passagem do rio Paraíba, se chegava à vila de Santo Antônio de Caraguatatuba que, já em 1640 com a fundação da vila de Ubatuba, foi gradativamente perdendo importância logística na ligação do planalto com o litoral. É inclusive em Ubatuba "que vai desembocar a primeira via de acesso dos de Taubaté 
ao litoral, seu verdadeiro caminho do mar, ou 'caminho do mar de Ubatuba', como se lê nos textos da época” (HOLANDA, 2014b, p. 239).

Segundo à documentação relativa ao padre José de Anchieta, o trajeto entre a sede administrativa da capitania e o litoral, passando pela Borda do Campo (atual município de Santo André, na região do $A B C$ paulista) durava de quatro a cinco dias. Dois séculos depois, o tempo gasto se reduziu, na melhor das hipóteses, a três dias, mesmo considerando que muitos viajantes preferiam completá-lo em quatro, em virtude de ser inevitável o pouso e a parada antes do acesso à raiz da serra e após a viagem do Enguaguaçu à terra firme. Um manuscrito de autoria desconhecida e sem registro de data, intitulado "Itinerário da villa de Santos à cidade de São Paulo", estima em quatorze horas e meia a duração de toda a jornada no sentido inverso, ou seja, de subida desde Santos ao planalto até São Paulo. As etapas, segundo esse manuscrito, se subdividiam da seguinte maneira: se despendiam três horas e quarenta e cinco minutos na passagem do rio Cubatão, cerca de meia hora do mesmo Cubatão à raiz da serra, aproximadamente uma hora e meia para a escalada, e o resto do tempo, mais de nove horas, entre o alto da serra e a cidade (HOLANDA, 2014b, p. 54).

Tal trajeto, como qualquer outro feito ao longo de todo o século XVII, fazia-se em geral à moda indígena, isto é, por marcha a pé e em fila, pois o progresso representado pelo emprego de cavalos e bestas para a realização do transporte só se difundirá após a primeira grande expedição de animais realizada por Cristóvão Pereira de Abreu, em 1733, que partiu da Colônia do Sacramento, na banda oriental do rio da Prata, em direção à famosa feira de animais de Sorocaba, em território paulista. Antes disso, são raras as ocasiões que se apontam a presença de alguns poucos animais, como na expedição chefiada por Francisco Pedroso Xavier, em 1675, e na do Anhanguera, de 1722. Mesmo para a condução de cargas a curtas distâncias, os equinos eram parcamente utilizados, preferindo-se os carros de bois sempre que houvesse estrada carroçável, como no caso do caminho de Santo Amaro (HOLANDA, 2014b, p. 204).

O domínio sobre o território e o gentio da terra exercido pelos luso-brasileiros foram acachapantes. Por volta de 1628 , os bandeirantes já haviam massacrado todas as povoações nativas existentes ao longo de 350 léguas do planalto de Piratininga e, ao tentarem avançar também sobre a região da Bacia Platina, investiram barbaramente contra as reduções jesuíticas do Uruguai e do Tape. Por representarem verdadeiros obstáculos aos intentos do comércio colonial português, essas comunidades formadas por indígenas livres foram destruídas e sua gente preada. A região pertencente hoje ao Paraguai e cuja jurisdição à época abrangia os atuais estados brasileiros do Paraná, Santa Catarina, Rio Grande do Sul e Mato Grosso do Sul, sofreu intensamente as consequências da ação predatória dos bandeirantes. A existência das reduções era, em verdade, incongruente com o mundo colonial e, portanto, seu combate ocorreu, primeiro, por meio da "obra de devastação" dos bandeirantes e, num segundo momento, por operações militares conjuntas de portugueses e espanhóis para aniquilar em definitivo a República Guarani, a pretexto da execução do Tratado de Limites firmado em 1750 pelos governos de Lisboa e Madri (MONIZ BANDEIRA, 2012, p. 39-41). 
Importa salientar, contudo, que a investigação buarqueana a respeito da implantação no Brasil de uma civilização adventícia fornece um conjunto razoável de explicações sobre a decadência da atividade bandeirante na passagem do século XVII para o XVIII. Concebidas pelo historiador como um prolongamento das bandeiras, o desenvolvimento das monções de povoado assinala o atrofiamento das expedições preadoras de índios, embora a razão que as moveu inicialmente era a mesma que marcou o movimento das entradas.

Isto se deve basicamente a duas razões: a primeira é a incompatibilidade do comércio de índios escravizados com o sistema colonial mercantil em virtude da precariedade das rotas terrestres. Nesse sentido, os limites impostos pelo incipiente sistema de locomoção representavam obstáculos consideráveis ao estabelecimento de uma rede mercantil de cativos indígenas que pudesse se realizar de modo regular e em larga escala, tanto dentro como fora da capitania de São Paulo; e, a segunda razão, a qual é indissociável da primeira, consiste no principal problema colocado a esse movimento de prear mão de obra nativa que, segundo Alencastro, diz respeito ao seu caráter apartado dos negócios coloniais do Reino de Portugal, ou seja, do comércio metropolitano baseado no tráfico de negros africanos. Para o autor (2000, p. 126):

\begin{abstract}
Excluídos do negócio atlântico de gêneros tropicais, privilégio dos mercadores ligados às casas metropolitanas, os traficantes de índios não conseguiriam exportar os produtos das fazendas, os quais - na ausência de circulação monetária - serviriam de pagamento às compras de escravos nativos efetuadas pelos fazendeiros. Deveriam, portanto, recorrer aos negociantes das praças marítimas para efetuar as exportações. Ora, estes últimos se apresentavam, igualmente, como vendedores de escravos... africanos. Se fosse preciso esboçar uma hierarquia das causas que atrofiaram a formação de um mercado de escravos índios na América portuguesa, eu não hesitaria em situar acima de todos o fator que acabo de apontar.
\end{abstract}

Em suma, o constrangimento que a rede de caminhos por terra impunha ao comércio de índios domesticados, associado, como já assinalamos, ao diminuto emprego de equinos para a realização dos transportes e a todo um conjunto de diretivas e ordenamentos régios contrários à apropriação e mercantilização do gentio da terra, foi decisivo para o surgimento de uma nova empresa, de uma nova empreitada colonizadora que intensificou a dilatação do território colonial português ao ser estimulada pela descoberta de jazidas auríferas numa ampla região de fronteira, marcada pela existência de uma rede de percursos fluviais que se articula à Bacia Platina e à bacia hidrográfica do rio Amazonas.

Referimo-nos ao sistema Paraguai/Paraná (cf. QUEIROZ, 2011). Este último rio, é importante que se diga, tem como um dos seus afluentes o Tietê, percurso fluvial de onde partiam as frotas de comércio que demandavam os arraiais mineradores e as quais começam a aparecer quando o bandeirantismo já se encontrava em flagrante declínio. Buarque de Holanda (2014a, p. 93) insiste neste ponto ao afirmar que "as expedições ao sertão ocidental se transformaram de entradas mais ou menos aventurosas em 
viagens regulares, metodicamente organizadas". A propósito, o descobrimento pioneiro ocorrido em 1718 das minas mato-grossenses do Coxipó-Mirim, evento inaugural das monções, precedeu em apenas alguns anos a provável última grande expedição bandeirante de que se tem notícia, a jornada aos Goiases realizada sob o comando do segundo Anhanguera (HOLANDA, 1994, p. 135).

\section{Pirogas, balsas e igaras}

O monçoeiro ou o cuiabano representam, de acordo com Sérgio Buarque, o tipo social que se consolidou no século XVIII em São Paulo como o responsável pelas navegações fluviais, haja vista que o propósito dessas expedições mareantes era o auxílio às minas de ouro e o comércio com a remota zona mato-grossense. Nomes genéricos, portanto, para os que negociavam em Cuiabá, cuiabanos e monçoeiros exerceram forte influência, por meio de suas frotas comerciais, sobre freguesias e vilas que se formaram às margens do Tietê e de outros afluentes do rio Paraná, como o Verde e o Prado.

No entanto, embarcações feitas de casca de árvore, denominadas pelos indígenas de igaras, já haviam sido utilizadas muito antes de descobertas as minas do Cuiabá, na viagem ao sertão realizada pelo irmão Pedro Correia, da Companhia de Jesus, que partiu da capitania de São Vicente em 1551. Os homens da entrada que fez Antônio Dias Adorno, no ano de 1574, em demanda à serra das Esmeraldas também empregaram o mesmo tipo de embarcação (HOLANDA, 2014b, p. 253). Já as balsas eram mais frequentemente utilizadas pelos jesuítas na travessia do rio Paraná, especialmente no período das cheias e enchentes, quando as águas se agitam para além da normalidade. Como reportado pelo nosso historiador, o termo "balsa" aparece em alguns textos jesuíticos como referência às embarcações formadas por duas canoas monóxilas que, movidas a remos, serviam de flutuadores ao sustentarem uma plataforma de paus ou taquaras (HOLANDA, 2014b, p. 257).

Muitas das características das típicas pirogas indígenas (embarcações compridas e estreitas feitas com tronco escavado) foram preservadas pelos europeus e seus descendentes paulistas: canoas monóxilas sem quilhas, sem velas, sem leme e sem âncora. No entanto, na medida em que o tráfego fluvial ia se tornando cada vez mais intenso e regular, a partir do descobrimento das aluviões auríferas do Cuiabá, alguns aperfeiçoamentos foram sendo feitos ao perfil primitivo dessas canoas de pau. Segundo Buarque de Holanda (2014b, p. 277), a evidência acerca da adoção de técnicas adventícias de navegação se fez notar, primeiro, pelo aperfeiçoamento dos remos, que passaram a ser afinados na extremidade da pá, e, segundo, pela utilização de uma série de inovações como "varas com juntas de metal para a subida dos rios", barracas de baeta, cumieiras e cobertas de lona para a proteção da carga contra chuvas e assaltos do "gentio de corso", fossem ele caiapós, paiaguás ou guaicurus.

Não obstante ao que acabamos de pontuar, sabe-se que foi praticamente insignificante a influência europeia sobre as técnicas do fabrico das canoas, a escolha das espécies vegetais para sua construção e o próprio sistema de navegação. O predomínio da cultura indígena é frequentemente reforçado na obra de Sérgio 
Buarque, como na passagem de Caminhos e fronteiras na qual ele observa que os "primeiros moradores do arraial cuiabano" viviam de modo muito semelhante aos "índios coletores e caçadores". Tinham um modo de vida "andejo e inconstante" que só se poderia conceber "em largos espaços livres” (HOLANDA, 1994, p. 148). Sobre as canoas e a atividade de navegação propriamente ditas, Buarque de Holanda (1994, p. 146) acrescenta que:

Durante as viagens, ficava a parte central destinada à carga. À frente, no espaço livre, que não excedia de dois, e três metros, iam seis remeiros, além do piloto e do proeiro. Nos lugares encachoeirados, levava-se ainda um guia ou prático, por vezes dois, que trabalhavam alternadamente. Na mareagem, tanto como na técnica de construção naval, prevalecia decididamente a tradição indígena. A essa tradição pertence, por exemplo, o uso de os tripulantes remarem sempre de pé, uso que foi corrente não só no Brasil como em todo o continente americano antes do advento dos brancos.

O proeiro, segundo parece, era a figura mais importante da tripulação, pois levava a chave do caixão das carnes salgadas e também a do frasqueiro, comandava e governava a proa e, batendo com o calcanhar no chão, marcava o compasso das remadas.

O primeiro paulista a atingir as barrancas do rio Cuiabá foi Antônio Pires de Campos, cuja expedição visava prear o gentio coxiponé que vivia na região. 0 segundo, foi Pascoal Moreira Cabral que, comprometido também com a captura de índios, se deparou, em 1718, com granetes de ouro cravados nas ribanceiras do rio Coxipó-Mirim. As rotas, todavia, variavam. As primeiras incursões monçoeiras desciam o Tietê até sua foz, seguiam o curso do Paraná por meio de um dos seus afluentes da margem direita, em geral o Pardo e, em seguida, subiam o Anhanduí-Guaçu para ganhar as contravertentes do rio Paraguai e, assim, atingi-lo através de um dos seus afluentes orientais. A partir da subida do Paraguai, alcançava-se o São Lourenço e, por fim, o Cuiabá. Todavia, já a partir de 1720, pilotos, proeiros e práticos começaram a cogitar alterações nesse percurso, de modo que as canoas passaram a subir a parte encachoeirada do Pardo, situada na barra do Anhanduí-Guaçu, até o ribeirão de Sanguexuga, onde o divisor das bacias do Paraná e Paraguai apresenta sua menor largura, de cerca de duas léguas e meia de extensão, sendo, portanto, mais apropriado à realização da varação das canoas (HOLANDA, 1994, p. 143).

Há quem considere também que o percurso, sempre a partir do porto de Nossa Senhora Mães dos Homens de Araritaguaba (atual município de Porto Feliz), descia o Tietê e o rio Grande para, em seguida, subir o Anhanduí, acima da barra do rio Pardo, e atravessar a região de Vacaria, pela descida do Mbotetei (rio Aquidauana), para atingir o Paraguai e depois o Cuiabá (MAGALHÃES, 2008, p. 35).

Esselin (2016, p. 50-51) aprofunda a questão ao mencionar a existência à época de quatro roteiros que, com frequência, eram percorridos pelas monções, sendo uma primeira parte comum a todos e que partia, como acabamos de dizer, de Araritaguaba 
pelo Tietê e, depois, a jusante do rio Paraná quando se podia optar, primeiro, pela subida do rio Ivinhema 4 até o acesso ao rio Brilhante, pelo qual se buscava um porto, chamado Santa Rosa ou Sete Voltas, onde as tripulações costumavam abandonar as canoas. Deste ponto, a rota se fazia por terra até as cabeceiras do Nioaque ou Urumbeva, onde se adquiria novas embarcações e, pela descida de tais rios, atingiase o Miranda para depois se passar ao Paraguai, ao São Lourenço e, finalmente, ao Cuiabá rumo à área mineradora. Outra alternativa era pelo rio Verde, o qual subia-se até um salto onde também se costumava renunciar às canoas para se percorrer o trecho por terra durante cerca de 25 dias até o porto do rio Piquiri, onde se tomava novas canoas. Em seguida, atravessava-se os rios Correntes, Itiquira e São Lourenço até atingir o Cuiabá. O terceiro roteiro se fazia mediante as subidas do Pardo e do Anhandui até o Aquidauana e, deste, seguia-se o curso do Miranda e depois o do rio Paraguai, onde se navegava até o Cuiabá rumo à vila homônima. O quarto roteiro tinha por baliza a subida até os campos de Camapuã, onde a varação das canoas era bem mais curta em comparação às que tinham de ser feitas no percurso dos outros itinerários, atingia-se o ribeirão de mesmo nome para, depois, descer o Coxim até o Taquari e, então, prosseguir pelo roteiro convencional até Cuiabá.

As dimensões e a capacidade de transporte das canoas paulistas eram coerentemente compatíveis com os cursos fluviais dessas rotas que, em alguns trechos, apresentavam baixos volumes de água. Algumas embarcações chegavam a comportar até trezentas ou quatrocentas arrobas de mercadorias, além dos mantimentos consumidos no correr da viagem e que, via de regra, eram renovados na Fazenda Camapuã (HOLANDA, 1994, p. 147). Além disso, há evidências de que as características dessas embarcações estavam em sintonia com os aspectos do reino vegetal de onde elas derivavam, ou seja, eram forjadas pelos tipos florestais mais comumente encontrados na área do Tietê, onde haviam praticamente duas espécies mais adequadas à fabricação de canoas, a peroba e a ximbouva. O preço das embarcações podia variar bastante a depender do tamanho, da capacidade de transporte, do estado de conservação, do material utilizado e do tipo da canoa, se de pau ou de casca (HOLANDA, 2014b, p. 269-270). ${ }^{5}$

Evidências coligidas pelo nosso autor indicam que as canoas mediam de onze a treze metros de comprimento por um metro e meio de boca. As feitas com ubás podiam suportar um peso de no máximo duas mil arrobas. Dificuldade maior era com a varação por terra das embarcações para escapar aos trechos mais encachoeirados, trabalho que demandava cerca de cem a cento e vinte homens (HOLANDA, 2014b, p. 265). Para as canoas menores, com capacidade total de quatrocentas a quinhentas arrobas, era preciso mobilizar contingente inferior de cerca de quarenta a sessenta e cinco pessoas, de modo que, onde se fizesse necessária a varação, era comum se apelar para tripulantes de diversas embarcações.

E como, para ocupar tanta gente, se necessitava além de muitas embarcações, carga proporcionada ao número delas, que indenizasse as despesas feitas, segue-se que as viagens só podiam ser organizadas por negociantes de grosso 
cabedal e muito crédito, ou então por vários comerciantes que se cotizassem para as emergências da jornada. De qualquer forma era indispensável adiantarem-se os gastos na compra de canoas e ainda de cabos, ferramentas, e o mais que se fizesse mister para as reparar dos estragos que viessem padecer, sem falar nas provisões indispensáveis - que por sua vez diminuíam o espaço reservado à carga -, na aquisição de escravos para remarem e na paga e sustentação dos índios levados como práticos da navegação. E tudo isso era feito na esperança tão mal cumprida, muitas vezes, de que os preços subidos dos gêneros no Mato Grosso viessem a cobrir, com algum lucro, as somas empatadas no negócio (HOLANDA, 2014b, p. 266).

O trecho acima ilustra bem algumas das principais características dessas frotas comerciais que tinham por destino o Mato Grosso. Eram, como se pode depreender, viagens caras e bastante arriscadas, viáveis apenas aos comerciantes de grosso trato, ou seja, aos que tinham cabedais suficientes e acesso ao crédito para aparelhar e abastecer de mantimentos as inúmeras embarcações que compunham as frotas. Só assim, era possível a apenas alguns mercadores alimentar a esperança - "tão mal cumprida" - de recuperar o investimento realizado no alvissareiro mercado cuiabano.

Mas, afinal, qual era a origem desses comerciantes e exploradores que arriscavam a própria vida, e a dos outros tripulantes, em expedições de resultados tão incertos, em viagens repletas de infortúnios e imprevistos? Em Monções, a resposta é precisa: tratavam-se, sobretudo, de ituanos e sorocabanos, embora houvessem também naturais de Jundiaí, São Paulo e Santana do Parnaíba entre os principais aventureiros que conseguiram, entre 1720 e 1820, acumular alguma fortuna com o auspicioso, porém imprevisível, comércio cuiabano.

Com base em informações contidas nos maços populacionais de Porto Feliz, Buarque de Holanda (2014b, p. 283) arrolou os principais produtos paulistas de exportação destinados a abastecer o mercado de Cuiabá. Dentre os gêneros mais frequentemente comercializados, encontrava-se, além de peças de artilharia e tecidos de pano grosso feitos de algodão, toucinho, arroz, tabaco, feijão, aguardente, farinha de milho e, obviamente, canoas, cujos preços variavam entre $12 \$ 000,32 \$ 000$ e $64 \$ 000$ ao final do século XVIII. Oscilando consideravelmente ao longo do tempo, o preço de uma canoa grande podia chegar a $80 \$ 000$ e o de um batelão a $25 \$ 000$, em 1812 .

A instalação da Fazenda Camapoã, sítio de pouso quase que compulsório aos monçoeiros, onde era possível reabastecer provisões, se agasalhar, descansar e, eventualmente, adquirir animais de carga para a realização do transporte por terra, constitui fator da extrema relevância para a história do comércio de Cuiabá (HOLANDA, 2014b, p. 321). Fundada na década de 1720 pelos irmãos João e Lourenço Leme, tal fazenda foi confiscada e concedida como sesmaria à Luiz Rodrigues Villares pelo governador e capitão-general de São Paulo à época, Rodrigo César de Menezes (cf. ALMEIDA, 1951). Não obstante, Buarque de Holanda (2014b, p. 325) observa o seguinte: 
Situada ao meio da rota do comércio do Cuiabá, em posição imposta pela geografia aos pioneiros da ocupação efetiva do Brasil Central, estaria Camapoã fadada, porventura, a converterse em entreposto mercantil de primeira grandeza, se o declínio da mineração e a concorrência, mais tarde, de outras vias de acesso não tivessem aniquilado essas possibilidades. [...]

Lugar de passagem quase obrigatória para uma zona pioneira, Camapoã parece ter permanecido, entretanto, estranhamente alheia à agitação tumultuosa dos centros auríferos. Contentou-se com um ritmo sonolento e rotineiro de velha fazenda sertaneja, mal interrompido, de vez em quando, pelo movimento das frotas ou pelo alarme causado pelas proezas cada vez menos frequentes dos caiapós vizinhos. Viveu parasitariamente à margem das ambições dos caçadores de ouro e de aventuras, preferindo os lucros mais seguros da carregação das canoas e da venda dos gêneros aos navegantes ou passageiros.

Havia mais de seiscentas cabeças de gado bovino em Camapoã no ano de 1751, além do cultivo de legumes, feijão, milho e arroz. Durante o pouso, que raramente durava período inferior a uma semana, os negociantes de Cuiabá se abasteciam, dentre outros gêneros, de fumo em rolo, aguardente de cana-de-açúcar, galinhas e carnes de vaca e de porco, enquanto aguardavam a realização do serviço de transporte das canoas a cargo dos sócios da Fazenda. Consta que, em 1788, a varação de cada canoa custava $20 \$ 000$ e a carrada $9 \$ 600$, configurando-se assim em fonte apreciável de lucro aos seus promotores (HOLANDA, 2014b, p. 326-328).

De qualquer forma, a atividade regular de navegação pelas "estradas móveis" teve um papel fundamental ao viabilizar também as comunicações do Mato Grosso com o Pará por meio do estabelecimento de mais uma importante via de comércio e que, desta feita, ampliou a fronteira econômica entre o Centro-sul e o Norte do país. Em virtude do desenvolvimento de uma nova via de comércio, agora terrestre, muitos mareantes abandonaram o percurso fluvial entre Porto Feliz e Cuiabá durante o segundo decênio do século XIX. Em 1818, comenta Buarque de Holanda (2014a, p. 98), o capitão-mor de Porto Feliz lamentava a ausência ali de "práticos, pilotos e proeiros para mais de seis ou oito canoas". Principalmente após a Independência, as monções de povoado se tornariam raras até seu total desaparecimento, por volta de 1838, quando uma epidemia de febre tifóide dizimou os ribeirinhos que viviam próximos às barrancas do Tietê, em particular, os últimos pilotos e práticos do antigo povoado de Araritaguaba.

\section{Caminhos terrestres e a viabilização dos gêneros de exportação no Oeste paulista}

Já há algum tempo, a historiografia tem dado destaque tanto aos casos de sucesso como de fracasso de comerciantes luso-brasileiros que se envolveram em "arriscosa função"6 junto às minas de Goiás e Mato Grosso. Em estudo cuja orientação coube à Sérgio Buarque sobre a trajetória empresarial do coronel Antônio da Silva Prado (o barão de Iguape), Petrone (1976) nos confirma que, antes de se tornar grande 
arrematante de contratos de impostos em São Paulo, Antônio Prado havia buscado recuperar seu cabedal no sertão de Caitité, na Bahia, após lograr considerável insucesso no comércio com a capitania de Mato Grosso. No sertão baiano, os negócios do algodão possibilitaram ao barão recuperar suas finanças, pois, ao que tudo indica, ele tardou em chegar a tempo para conseguir fazer fortuna com a atividade aurífera da região mato-grossense. Sérgio Buarque, ao prefaciar o livro de Petrone, menciona a variedade de gêneros com os quais o barão negociou durante sua permanência em Caitité: "fustão, cambrainhas, morins, meadas de lã, lenços de cassa, baetas, chitas, linha, às vezes tabaco, açúcar, papel, vinhos, pregos, milho, farinha, sabão do reino" (HOLANDA, 2017, p. 248-249).

Comerciante hábil, capacitado nos meios mercantis pelos seus tios, os também negociantes Eleutério Prado e Manuel Rodrigues Jordão, Antônio Prado se destacaria, a partir do segundo decênio do século XIX, como grande tropeiro e negociante de gado em sociedade formada com João da Silva Machado, o barão de Antonina. Foram, portanto, fundamentalmente as tropeadas, bem como a arrematação de contratos de cobrança de impostos em alguns registros de passagem, que conferiram ganhos financeiros substanciais a esse baronato que, por sua vez, os permitiu transformá-los em capital, diversificar os negócios e alavancar a carreira de negociantes e grandes fazendeiros de alguns dos seus descendentes.

Buarque de Holanda (2017, p. 246) comenta, por exemplo, a respeito do coronel Luís Antônio de Souza, negociante de grosso trato e um dos casos de incontestável sucesso de paulistas que enriqueceram com o comércio em Mato Grosso e Goiás. Segundo o tombamento provincial de 1817, o futuro brigadeiro Luís Antônio figura como o maior proprietário de escravos de São Paulo (290 cativos), seguido pelo sargento-mor Manuel José de Melo que mantinha 180 cativos em sua fazenda em Guaratinguetá (HOLANDA; MAIA, 2017, p. 279).7

A seguir, destaca-se um longo e significativo trecho prefacial no qual Buarque de Holanda (2017, p. 247) discorre sobre o modus operandi de certos membros da família do barão de Iguape, logo, dessa elite econômica, política e empresarial do período da Independência.

É o caso do próprio brigadeiro Jordão e do capitão Eleutério da Silva Prado, seus tios, assim como de um primo, Antônio de Queirós Teles (futuro barão de Jundiaî) e pelo menos dois outros parentes próximos que se fixaram no Cuiabá, onde constituíram família e deixaram descendentes. Como os negócios a crédito eram de uso amplo naquelas minas e os devedores não tinham, em geral, muita pressa em saldar débitos, quando os saldavam, é de supor que resultariam em grandes lucros para quem se sujeitava a tamanhos riscos. Não raro chegavam a apelar para o poder público no sentido de chamar este à ordem o devedor faltoso. Há uma carta, por exemplo, de Eleutério Prado, tio de Antônio, datada de 1812 e endereçada a Oeynhausen, capitãogeneral de Mato Grosso antes de ir exercer o mesmo cargo em São Paulo, onde é recomendado seu sobrinho Antônio de Queirós Teles, que levava bestas e cargas para ir dispor nas 
minas, e onde é pedida ainda a proteção do general para o propósito do dito sobrinho de fazer ali a cobrança de dívidas velhas para com a sua fazenda. No mesmo ano de 1812 vai dirigir-se Luís Antônio de Sousa também a Oeynhausen, com pedido semelhante e, em 1814, com outro. Era antigo o costume, pois que já em 1773 pedia o mercador santista Bonifácio José de Andrada, por intermédio do governador de São Paulo, ao morgado de Mateus, ao capitão-general Luís Albuquerque, de Mato Grosso, que fizesse pressão sobre seus devedores, pois ainda devia ser embolsado ali da quantia de $1.068 \$ 84$. Do que Ihe era devido, só tinha recebido, até então, e as dívidas foram contraídas muitos anos antes, o pagamento de duzentas oitavas de ouro, equivalentes, no todo, a trezentos mil-réis.

Interessante nesse trecho é notar como era comum, entre os membros dessa elite paulista da época, o empréstimo a crédito e a venda a fiado. Atividades que se realizavam por meio de "contratos" de alto risco, mas que, quando honrados, podiam render bons lucros. Para se efetuar as transações, "o comprador dava fiadores para o pagamento a prazo, e os juros da lei sobre o principal, na base de $5 \%$ ao ano, começavam a correr depois de uma espera estipulada de antemão,..." (HOLANDA, 2017, p. 247). Via de regra, os adventícios optavam, primeiramente, pelas atividades do comércio por serem mais rentáveis numa economia colonial com forte viés mercantil, inclusive em zonas de fronteira, para somente depois de acumular certo cabedal investirem na aquisição de escravos e na produção de gêneros agrícolas demandados pelo mercado transatlântico, como o algodão, o açúcar, o tabaco e o café. Quando se alcançava determinado nível de acumulação de capital, o negociante-empresário passava também a atuar como ofertante de crédito.

Essa foi a trajetória de alguns dos principais proprietários de engenho e grandes cafeicultores de São Paulo, como o já citado brigadeiro Luís Antônio, que detinha grandes extensões de terras e plantéis consideráveis de escravos na região de Campinas, e o tenente-coronel Antônio Carlos de Arruda Botelho, futuro conde do Pinhal, que, antes de assumir a posse das terras deixadas pelo seu pai Calos José Botelho, onde hoje se localizam os municípios de São Carlos e Ribeirão Bonito, optou por liquidar o seu armazém de secos e molhados que mantinha em Piracicaba.

Praticamente a totalidade da porção Oeste do território paulista situada à margem esquerda do Tietê foi sendo povoada e se desenvolveu na medida em que freguesias e vilas iam sendo fundadas e, com o passar do tempo e em períodos distintos, iam se integrando aos mercados da pecuária e de gêneros de subsistência vinculados, primeiro, à atividade mineradora da região de Goiás e Mato Grosso e, em seguida, às economias canavieira e cafeeira. A faixa de terra localizada no chamado Oeste paulista entre os rios Piracicaba e Mogi-Guaçu, em particular o eixo formado pelos municípios de Rio Claro', São Carlos do Pinhal e Araraquara, é emblemática nesse sentido.

São Bento de Araraquara se tornou freguesia do município de Itu em 1817 e, pouco tempo depois, em 1821, teve sua administração transferida para a vila de Piracicaba, que havia adquirido autonomia administrativa nesse mesmo ano adotando 
a designação de Vila Nova da Constituição. Em 1832, Araraquara também conquista sua autonomia administrativa tornando-se vila e, em 1889, chega à categoria de cidade (SILVA; PIQUEIRA, 2010). Portanto, a região conhecida como "sertão de Araraquara" começou a ser ocupada devido à atitude de capitães-mores de Itu, Sorocaba e Porto Feliz, vilas mais antigas fundadas por bandeirantes respectivamente em 1654, $1661 \mathrm{e}$ 1797, que costumavam enviar criminosos e degradados às áreas remotas de matas densas mais a Noroeste do território paulista. Para Cincinato Braga (2007), a expressão "sertões de Araraquara" se referia à zona hoje sob influência dos municípios paulistas de Rio Claro, Itirapina, Descalvado, São Carlos, Dourado, Brotas, Jaú e Araraquara.

De acordo com Dean (1977, p. 39), os sesmeiros originais dessa extensa região a partir de Rio Claro, bem como os indivíduos que adquiriam posteriormente tais concessões de terra, eram membros de famílias que viviam e, em alguns casos, cultivavam cana-de-açúcar no "quadrilátero do açúcar", em especial em Itu e Campinas. Dentre tais sesmeiros está Manoel Martins dos Santos Rego, cirurgião-mor natural de Itu que, pouco tempo depois de receber três léguas em quadra de terras, as vendeu ao capitão Carlos Bartholomeu de Arruda, também da vila de Itu, pelo valor de 30\$960, segundo escritura de 30 de março de 1786 (BRAGA, 2007, p. VIII). Em seguida, Carlos José Botelho herdou a posse das terras, que, em virtude do seu falecimento em 1854, foram repassadas, como já dissemos, ao seu filho, o conde do Pinhal, uma das personalidades mais expressivas e influentes do cenário político e econômico da região durante o período imperial. ${ }^{10}$

Antônio Carlos de Arruda Botelho recebeu os títulos de barão, visconde e, finalmente, conde do Pinhal, face sua colaboração com os objetivos do governo do Império através da fundação e efetiva ocupação da região do planalto paulista entre Rio Claro e Araraquara. Em 1856, ele registrou suas propriedades fundiárias e um título de uma parte da sesmaria do Pinhal junto ao governo provincial de São Paulo. Igualmente ao pai, seguiu carreira pública em Araraquara como juiz municipal e presidente da câmara local entre 1857 e 1860. Foi proprietário de diversas fazendas da região (Pinhal, Santo Antônio, Lobo, Palmital, Serra, entre outras) e, ademais, foi uma figura central na fundação da vila de São Carlos do Pinhal (hoje designada apenas por São Carlos), com destacada atuação no abastecimento de tropas mercantis e militares (principalmente durante a Guerra do Paraguai) e na construção e manutenção de estradas visando facilitar o percurso das expedições que seguiam para Mato Grosso e Goiás. Sobre as vias de comunicação, Petrone (1968, p. 187-188) tece observações interessantes ao citar a opinião do capitão-geral Antônio de Melo Castro e Mendonça, governador de São Paulo entre junho de 1797 e novembro de 1802:

O sistema viário de São Paulo era verdadeiro obstáculo para o maior desenvolvimento da cultura canavieira em "serra acima". Todos os governadores, a começar pelo Morgado de Mateus, perceberam o fato. Melo Castro e Mendonça, ao limiar da era do grande desenvolvimento da cultura da cana, escreveu, em 1800: A cana-de-açúcar "vegeta igualmente bem de Serra acima, e na Marinha; e supposto que o produto de Serra acima seja mais abundante, e a manipulação menos complicada"... "com tudo 
o transporte para o lugar de embarque, e alguma dannificação, que adquire o dito genero no mesmo transporte fazem, que seja menos lucrativa a sua cultura nesta Situação, por este motivo quazi todo o assucar que se embarca em Santos degenera da sua qualidade ao ponto de ficar em descredito hum produto, que comparado aqui com o melhor de Serra abaixo não se Ihe conhece differença". Mais adiante, em 1802, escrevia em sua Memoria dedicada ao sucessor:... "notei que huma das causas da dannificação do assucar era a má preparação que de proposito Ihe faziam, não o purificando da parte extractiva, que ao menor toque da humidade se dissolve e com ellas as partículas do assucar. Isto posto, o único meio que ha para evitar a alteração que pela humidade se ocasiona no assucar hé a conservação das estradas.

Como é possível notar, a questão das estradas vinha sendo discutida como um dos pontos nefrálgicos impostos à administração reinol em São Paulo, especialmente a partir da virada para o século XIX, já que a precariedade dos caminhos terrestres implicava em baixas cotações de preço dos produtos embarcados e, assim, reduziase a rentabilidade da produção em decorrência da piora de qualidade, num primeiro momento, do açúcar, e, em seguida, da de outros gêneros de exportação, como o café.

A hipótese que se pode lançar a partir da análise da historiografia sobre São Paulo é a seguinte: os caminhos carroçáveis percorridos pelas tropas de animais cargueiros teriam gerados efeitos dinamizadores à produção canavieira semelhantes, em termos proporcionais, aos acarretados pelos caminhos de ferro à economia cafeeira? Há indícios que nos leva a crer que sim, pelo menos para a região do planalto até Rio Claro, no Oeste paulista. Ou seja, para as unidades produtivas "serra acima" situadas além desse município, no contexto portanto anterior à implementação do transporte ferroviário na região ${ }^{11}$, o investimento realizado não compensava nem ao produtor de café, eliminando, assim, a vantagem que este gênero possui, segundo a bibliografia, em termos de resistência e durabilidade comparado ao açúcar, que se deteriora mais facilmente em virtude, por exemplo, da exposição à umidade.

Sabe-se que as perdas decorrentes das dificuldades com o transporte serão definitivamente superadas após 1867, com a inauguração da estrada de ferro entre Santos e Jundiaí e, logo em seguida, com a criação pelo capital cafeeiro de diversas companhias ferroviárias que se instalaram a partir de São Paulo, Jundiaí e Campinas e se expandiram por todo o interior da província de São Paulo. Entretanto, é possível identificar dois eventos ocorridos anteriormente que caracterizam melhoramentos de suma importância à questão viária relacionada à exportação do açúcar produzido no planalto paulista.

O primeiro deles foi o calçamento do velho caminho do mar, entre São Paulo e Cubatão, realizado na gestão de D. Bernardo José de Lorena e Silveira à frente do governo paulista e concluído no início de 1792. Com a "calçada do Lorena", a descida da serra pelas tropas de muares foi significativamente facilitada, embora o caminho a partir da borda do rio Cubatão até Santos continuou sendo feito por via fluvial, 
acarretando frequentes prejuízos à produção em função dos trechos excessivamente rasos e das constantes tormentas que costumavam embaraçar o fluxo de balsas e canoas, seja virando-as ou inundando-as, o que de qualquer forma acabava por deteriorar o carregamento de açúcar a ser exportado (PETRONE, 1968, p. 193-194).

O segundo episódio que conferiu alento considerável à atividade açucareira em São Paulo foi a construção de um caminho terrestre exatamente nesse trecho entre Cubatão e Santos. Tal complemento à calçada do Lorena só foi inaugurado em fevereiro de 1827, não obstante às constantes reclamações por parte dos condutores de tropas devido à insuficiência dos trabalhos de manutenção, principalmente das pontes, associada à escassez de mão de obra para a realização periódica de tais serviços de conservação da estrada (PETRONE, 1968, p. 199).

Nas atas do Conselho Geral da Província de São Paulo que, ao lado do Conselho da Presidência da Província, era o órgão parlamentar deliberativo existente antes da criação das Assembleias Legislativas, em 1835, a preocupação com as condições e o custo de manutenção das estradas continuava a aparecer com frequência, especialmente em relação à estrada que ligava o planalto ao porto de Santos. O poder provincial já tinha competência para legislar sobre a matéria da provisão dos meios de transporte desde a lei geral de 29 de agosto de 1828. No entanto, desde a primeira lei ferroviária datada de 31 de outubro de 1835 até a segunda lei, a de 26 de junho de 1852, nenhuma companhia chegou a ser organizada no país devido à ausência de mecanismos institucionais que dessem garantias aos pesados investimentos necessários para se construir e operar uma estrada de ferro.

O tema da concorrência entre os diferentes meios de transporte é, portanto, anterior ao início propriamente das operações das linhas férreas no país, visto que o debate parlamentar a esse respeito já ocorria antes mesmo de concluída as primeiras obras de construção dessas vias. A concorrência entre modais se verificava, já desde o início do século XIX, não em relação à disputa por usuários, por "clientes", isto é, no âmbito do consumo desses serviços de transporte, mas, fundamentalmente, ela se verificava em função da demanda por mão de obra. Qual seria o contingente disponível para a construção dessas vias de transporte, fossem elas estradas de rodagem ou ferrovias? Qual deveria ser o nível médio dos salários desses trabalhadores? Quem deveria financiar tais vias de comunicação? Havia à época alguma estimativa de retorno aos construtores e empreiteiros e qual deveria ser o grau de envolvimento do poder público nessas obras? Essas eram algumas das questões que foram temas de longos debates legislativos no âmbito da Assembleia Provincial.

Nesse passo, convém retomarmos um questionamento formulado por Sérgio Buarque acerca dessa questão em particular, a saber, a do emprego da mão de obra nos serviços de transporte em São Paulo entre meados do século XVIII e a primeira metade do XIX. Para o nosso historiador (HOLANDA, 1994, p. 130-131, grifo nosso):

Já por essa época não seriam muito numerosos, em São Paulo, os índios de carga, substituídos, cada vez mais, pelos cavalares e muares. O que representaria, sem dúvida, progresso notável na rapidez dos negócios, além de poupar trabalhadores, em um 
momento em que a mão-de-obra indígena era menos abundante, e em que os negros, excessivamente dispendiosos, ficavam geralmente reservados às fainas agrícolas. Já se indicou como um primeiro obstáculo a esse progresso tinha sido a insuficiência das estradas, criadas unicamente para uso de pedestres. Além disso, à escassez de cavalares corresponderia, durante longo tempo, a existência de índios de serviços especialmente dedicados ao transporte de fardos e passageiros, sobretudo através do Paranapiacaba. Sem falar nos bastardos e mamelucos, que faziam o mesmo trabalho mediante remuneração. Em que situação não iria ficar essa gente, quase imprestável, muitas vezes, para outro mister, uma vez suprimido seu principal meio de vida?

\section{Considerações finais}

Caminhos e fronteiras é, sem sombra de dúvidas, a obra que enlaça essa agenda de pesquisa de Sérgio Buarque dedicada à conquista do território, ao estabelecimento de rotas mercantis e, portanto, à implantação e administração do comércio de escravos e mercadorias na região Centro-sul do Brasil. Percebe-se, em seus escritos, uma narrativa crítica apurada, e sistematicamente ancorada em fontes primárias diversas, que indica ter havido no país entre os séculos XVI e XIX uma evolução gradativa das modalidades de transporte, que vai do apressamento e dos descimentos de indígenas até o advento das ferrovias, passando pelas monções de povoado e pelas tropas de muares.

Esse projeto luso-brasílico de conquista e exploração, executado especialmente pelos paulistas (isto é, bandeirantes, índios de serviço, mamelucos, tropeiros e negociantes), definiu trajetos, estabeleceu roçados, constituiu povoados, fundou vilas e criou sociabilidades específicas, enfim, estruturou uma rede de negócios marcada por um fluxo cada vez maior de pessoas, minérios, mantimentos de relativa variedade e gêneros agrícolas de exportação.

O questionamento de Sérgio Buarque acima destacado vai ao encontro de um dos problemas centrais enfrentado pelos governos provinciais e imperial no Brasil: o problema da disputa pela mão de obra disponível. Disto decorre, dentre outras coisas, a existência ao longo do tempo de um conflito de interesses em torno do tipo de política pública de transporte que parlamentares e membros do executivo esperavam apoiar, além do próprio desenvolvimento dos meios de transporte, que envolve empreiteiros, contratadores, financistas, produtores rurais, comerciantes, industriais e homens públicos. Em paralelo a isso tudo, não se pode perder de vista a inerente necessidade de locomoção dos indivíduos e a esperança daqueles que necessitam de um serviço regular e eficiente para transportar a produção de gêneros mercantis de toda a espécie, seja no sentido das exportações ou no das importações, para atender a uma gama de demandas das populações que vivem nas distintas regiões desse enorme e portentoso país continental chamado Brasil. 


\section{Referências}

ALENCASTRO, L. F. de. O trato dos viventes: formação do Brasil no Atlântico Sul. São Paulo: Companhia das Letras, 2000.

ALMEIDA, M. M. de. Episódios históricos da formação geográfica do Brasil: fixação das raias com o Uruguai e o Paraguai. Rio de Janeiro: Pongetti, 1951.

ARAÚJO, M. L. V. Os caminhos da riqueza dos paulistanos na primeira metade do oitocentos. São Paulo: Hucitec, 2006.

BLAJ, I. Pulsações, sangrias e sedimentação: Sérgio Buarque de Holanda e a análise da sociedade paulista no século XVII. In: NOGUEIRA, A. R. et al. (org.). Sérgio Buarque de Holanda: vida e obra. São Paulo: Secretaria do Estado da Cultura/Arquivo do Estado/Universidade de São Paulo/Instituto de Estudos Brasileiros, 1988, p. 83-85.

BORREGO, M. A. de M. et al. Trajetória e reconstituição digital de uma canoa do Museu Paulista - USP. Anais do Museu Paulista, v. 27, p. 1-40, 2019.

BRAGA, C. Contribuição ao estudo da história e geografia da cidade e município de São Carlos do Pinhal. In: Almanach de 1894. São Carlos: Imprensa Oficial do Estado de São Paulo/Ed. UFSCar, 2007 [1893], p. III-LII.

DEAN, W. Rio Claro: um sistema brasileiro de grande lavoura, 1820-1920. Rio de Janeiro: Paz e Terra, 1977.

ELLIS JUNIOR, A. O café e a Paulistânia. São Paulo: Universidade de São Paulo, 1951.

ESSELIN, P. M. A fazenda Camapuã. Cadernos do LEPAARQ, v. 13, n. 26, p. 48-65, 2016.

GRANDI, G. Café e expansão ferroviária: a Companhia E. F. Rio Claro (1880-1903). São Paulo: Annablume/Associação Pró Casa do Pinhal, 2007.

HOLANDA, S. B. de. Caminhos e fronteiras. 3a. ed. São Paulo: Companhia das Letras, 1994.

HOLANDA, S. B. de. Monções. Organização de Laura de Mello e Souza e André Sekkel Cerqueira. Notas de André Sekkel Cerqueira. 4a. ed. São Paulo: Companhia das Letras, 2014a.

HOLANDA, S. B. de. Capítulos de expansão paulista. Organização de Laura de Mello e Souza e André Sekkel Cerqueira. Notas de André Sekkel Cerqueira. São Paulo: Companhia das Letras, 2014b.

HOLANDA, S. B. de. O barão de Iguape. In: Livro dos prefácios. 2a. ed. São Paulo: Companhia das Letras, 2017, p. 238-250.

HOLANDA, S. B. de; MAIA, T. Vale do Paraíba - Velhas fazendas. In: Livro dos prefácios. 2a. ed. São Paulo: Companhia das Letras, 2017, p. 251-297. 
MAGAlHÃES, L. A. M. Rio Paraguay da Gaíba ao Apa. Campo Grande: Alvorada, 2008.

MELLO, E. F. de. Na quadrada das águas perdidas. São Paulo: Rio do Gavião/Discos Marcus Pereira, 1979 (obra fonográfica).

MONIZ BANDEIRA, L. A. A expansão do Brasil e a formação dos Estados na Bacia do Prata: Argentina, Uruguai e Paraguai (da colonização à Guerra da Tríplice Aliança). 4a. ed., rev. e ampl. Rio de Janeiro: Civilização Brasileira, 2012.

MONTEIRO, J. M. Negros da terra: índios e bandeirantes nas origens de São Paulo. São Paulo: Companhia das Letras, 1994.

PETRONE, M. T. S. A lavoura canavieira em São Paulo: expansão e declínio (17651851). São Paulo: Difusão Europeia do Livro, 1968.

PETRONE, M. T. S. O barão de Iguape: um empresário da época da Independência. São Paulo: Companhia Editora Nacional, 1976.

QUEIROZ, P. R. C. "Caminhos e fronteiras": vias de transportes no extremo oeste do Brasil. In: GOULARTI FILHO, A.; QUEIROZ, P. R. C. (orgs.). Transportes e formação regional: contribuições à história dos transportes no Brasil. Dourados: Ed. UFGD, 2011, p. 99-138.

RIBEIRO, M. A. R.; CAMPOS, C. de. História da riqueza na economia cafeeira paulista: a família Arruda Botelho (1854-1901). Resgate, v. XX, n. 24, p. 59-73, 2012.

SCHNEIDER, A. L.; MARTINS, R. A expansão paulista em Afonso de Taunay e Sérgio Buarque de Holanda: reflexões e trajetórias. Revista de História, n. 178, p. 1-27, 2019.

SILVA, F. S. da; PIQUEIRA, M. T. Os municípios do estado de São Paulo. In: ODALIA, N.; CALDEIRA, J. R. de C. (orgs.). História do estado de São Paulo: a formação da unidade paulista. São Paulo: Ed. Unesp/Imprensa Oficial/Arquivo Público do Estado, 2010, p. 67-298.

TAUNAY, A. de E. História das bandeiras paulistas. 2a. ed. São Paulo: Edições Melhoramentos, 1961. Tomo I.

VILARDAGA, J. C. Fronteiras instáveis e alianças cambiantes: a ocupação colonial do Guairá e as relações entre Villa Rica del Espiritu Santo e São Paulo de Piratininga entre os séculos XVI e XVII. Revista de Indias, v. LXXIX, n. 277, p. 659-695, 2019. 


\section{Notas}

1 Ressalva-se, no entanto, que a discussão a respeito da análise crítica de Sérgio Buarque de Holanda sobre o bandeirantismo, em oposição à uma leitura idealizada da figura do bandeirante como "desbravador" e "integrador glorioso do território nacional", frequentemente associada à obra de Affonso de Taunay, não consiste em um dos nossos objetivos neste artigo. Sobre esse antagonismo metodológico, que opõem as abordagens de Taunay e Buarque de Holanda, consultar SCHNEIDER e MARTINS (2019). Para eles, Buarque de Holanda identifica como fundamental nas expedições bandeirantes "o interesse cobiçoso de formação de mão de obra escrava para lavouras [...]", em oposição à visão enaltecedora de Taunay do bandeirante como figura histórica central para a formação da nacionalidade brasileira (SCNHNEIDER; MARTINS, 2019, p. 5). Para um aprofundamento sobre o referido antagonismo, ver também BLAJ (1988).

2Expressão retirada do texto da canção "Chula no terreiro", que compõe a obra fonográfica Na quadrada das águas perdidas, de Elomar Figueira de Mello (1979).

${ }^{3}$ A respeito por exemplo da introdução das primeiras reses em Assunção, possessão do Reino de Castela, que, ao que tudo indica, foram levadas por balsas que partiram de São Vicente, Buarque de Holanda (2014b, p. 272) observa que: "Pouco mais se sabe dessa viagem porém, além do fato de ter sido realizada às escondidas das autoridades portuguesas, e de que gastaram os expedicionários cinco meses até alcançarem um porto junto ao rio Paraná, de onde tiveram licença para ir por terra a Assunção."

${ }^{4}$ A propósito, Buarque de Holanda (2014b, p. 309) escreveu: "Mais antiga, talvez, do que a rota Pardo-Anhanduí foi a do Ivinheima, outro afluente do Paraná. Sabendo-se que muitos sertanistas, nos primeiros tempos, frequentaram, de preferência ao Tietê, o Paranapanema, que era estrada mais fácil para as reduções do Guaíra, nada há que admirar nessa escolha. Para atingi-lo na parte navegável, aqueles que saíam de São Paulo caminhavam catorze ou quinze dias a pé, e, em seguida, rodando esse rio água abaixo, iam dar no Paraná. O Ivinheima, embora corra em direção contrária, é, do outro lado do Paraná, quase um prolongamento da estrada fluvial representada pelo Paranapanema. Uma vez verificada sua navegabilidade, que explorações mais recentes comprovaram, tudo indicava que seria essa a passagem natural para os campos da Vacaria e as fundações do Itatim.Segundo se lê em velho roteiro bandeirante, depois de subir por algum tempo o Ivinheima, costumavam os sertanistas tomar um dos seus formadores, provavelmente o Vacaria, e, ao cabo de dezoito dias de navegação, iam ter a um sítio onde deixavam as canoas e faziam suas roças de plantação. Desse ponto caminhavam por terra durante oito dias, pouco mais ou menos, e atingiam as cabeceiras do Aquidauana."

5 Sobre as características materiais das canoas paulistas, consultar BORREGO et al. (2019).

6 Tem o sentido de "uma festa arriscada, com perigos próprios, até mesmo por ser em lugar de difícil acesso” (MELLO, 1979).

7 Para um aprofundamento a respeito da riqueza acumulada pelos comerciantes de grosso trato de São Paulo durante a primeira metade do século XIX, recomenda-se o trabalho de ARAÚJO (2006).

${ }^{8}$ Fundada em 1857, São Carlos tornou-se freguesia do município de Araraquara em 24 de maio de 1858 e, em 1865, foi elevada à condição de vila conquistando assim sua autonomia administrativa. Em 21 de abril de 1880, recebeu os foros de cidade. Já o povoado de Bom Jesus do Ribeirão Bonito surgiu em torno de uma capela erguida em 2 de março de 1872; tornou-se freguesia do município de Brotas em 8 de março de 1882 e conquistou a autonomia administrativa ao ser elevada à categoria de vila em 5 de março de 1890 (SILVA; PIQUEIRA, 2010, p. 238 e 262). 
9 "Povoado fundado por bandeirantes no século XVIII, que viajavam para Cuiabá em busca de ouro. Inicialmente recebeu o nome de São João Batista do Ribeirão Claro. Sendo uma região de solo fértil, atraiu muitos agricultores que ali formaram fazendas onde cultivaram cana-de-açúcar e criaram animais, com base de sua economia no século XIX, o que possibilitou um considerável desenvolvimento. Decorrente disso, tornou-se freguesia do atual município de Piracicaba em 9 de dezembro de 1830, e teve sua administração transferida para o município de Limeira em 8 de março de 1842. Três anos mais tarde, conquistou a autonomia administrativa ao ser elevada à condição de vila. Posteriormente, em 30 de abril de 1857, recebeu os foros de cidade." (SILVA; PIQUEIRA, 2010, p. 242).

${ }_{10} \mathrm{~A}$ respeito da formação do patrimônio (composição da riqueza) e da diversificação dos negócios da família Arruda Botelho, indica-se o artigo de RIBEIRO e CAMPOS (2012).

${ }^{11}$ A esse respeito, sugere-se a leitura de GRANDI (2007).

\section{Nota do Editor}

A revista História (São Paulo) agradece à FAPESP pelo apoio financeiro, na modalidade Auxílio à Pesquisa - Publicações/Periódicos (Processo n. 2020/04324-9), para a publicação deste artigo.

Guilherme GRANDI. Professor doutor do Departamento de Economia da Faculdade de Economia, Administração e Contabilidade da Universidade de São Paulo (FEA/USP), do Programa de PósGraduação em Economia (FEA/USP) e do Programa de Pós-Graduação em História Econômica da Faculdade de Filosofia, Letras e Ciências Humanas da Universidade de São Paulo (FFLCH/USP). Possui graduação em Ciências Sociais pela Universidade Estadual Paulista Júlio de Mesquita Filho (2002), mestrado em Economia pela Universidade Estadual Paulista Júlio de Mesquita Filho (2005) e doutorado em História Econômica pela Universidade de São Paulo (2011). Em 20122013, foi pesquisador de pós-doutorado no Centre interuniversitaire de recherche en économie quantitative (CIREQ) da Université de Montréal (Canadá). Tem experiência de pesquisa na área de Economia, com ênfase em História Econômica, atuando principalmente com os seguintes temas: transportes, economia cafeeira, imigração, Estado, industrialização, movimento operário, sindicalismo, políticas de transporte, história quantitativa e historiografia comparada entre Brasil, Argentina e Canadá. 